\title{
Is succession-based management of coastal dune forest restoration valid?
}

Matthew J Grainger* and Rudi J van Aarde

\section{Abstract}

Here we test the predictions of succession in a restoration context to ascertain the validity of succession-based management. Our study took place in seven coastal dune forest sites of various ages regenerating after mining disturbance. We used our $16 \mathrm{yr}$ of data on 4 taxa to test the predictions of succession theories. Patterns in turnover for all taxa showed a decelerating decrease contradicting Clements's classical theory of succession. Changes in composition followed patterns predicted by the individualistic model of succession. Trends in species diversity measures did not always match predictions with bird species diversity declining in most sites over time. Regional disturbances may explain this phenomenon. Succession-based management is a valid approach to dune forest rehabilitation as long as restoration managers recognise disturbance as an ecological reality.

Keywords: Coastal dune forest, Chronosequence, Mining, Rehabilitation, Succession, 
Introduction

The theory of succession has been a fundamental concept in ecology for over $100 \mathrm{yr}$ (at least since Cowles' publication in 1901) and is perhaps the most enduring of all ecological theories (Walker and del Moral 2008). This theory describes the progressive and deterministic change in species composition and dynamics over time and forms the conceptual basis of restoration ecology (Young et al. 2005). Successional theory may be ideal as a basis for restoration as it is conceptually simple and encapsulates the ability of ecosystems to recover from disturbances. The manipulation of this restorative ability is a fundamental concern of restoration ecology (Walker et al. 2007).

The use of successional theory to frame restoration management is common, but testing the predictions of this theory in a restoration setting is not (Walker and del Moral 2008, but see Prach and Pyšek 2001 and ̌̌ehounková and Prach 2008). Restoration practice often relies more upon horticulture, agronomy, and engineering than on succession (Hodačova and Prach 2003, Young et al. 2005). Hobbs and colleagues (2007) posit that this separation stems from cultural and conceptual differences between restoration practitioners and those studying succession. Many aspects of succession make it unattractive to restoration practitioners. For example, successional studies are often on a time scale of hundreds or thousands of years, whereas a restoration project may only last 20 or $30 \mathrm{yr}$ (Dobson et al. 1997). Importantly, there have been numerous examples of the failure of successional trajectories to achieve restoration targets (e.g., Zedler and Callaway 1999, Suding et al. 2004).

Many factors may render succession unpredictable, including priority effects (Connell and Slatyer 1977), edaphic and topographical heterogeneity (Cutler 2009), propagule 
availability, species dispersal (Lanta and Lepš 2009), persistence of pioneers (Tsuyuzaki 2009), herbivory (Baniya et al. 2009), and the sporadic establishment of strong dominants (Walker and del Moral 2003). In addition, the structure, composition, and connectivity of the landscape may also have strong effects on species composition (Grainger et al. 2011). These and other factors may compromise the efficacy of succession-based restoration management (Suding et al. 2004). Succession theory, however, offers several predictions of the trends in species composition and other community properties that can be expected after a disturbance event. The outcomes of restoration actions should be predictable using successional theory (Van Andel and Aronson 2006). Temporal trends expected from succession include directional changes in species composition, increased species diversity (in early succession at least; Connell 1978) and increased stability (Dobson et al. 1997).

Perhaps the most alluring aspect of succession for restoration ecology is the concept that after a disturbance event, habitats will predictably recover their former structure and function (Walker \& del Moral 2007). Accordingly, there will be a directional progression in species composition, which becomes more similar over time to an undisturbed community (Pickett et al. 1987; Wassenaar et al. 2005). The traits of species should also be predictable so that immediately after the disturbance, species with life histories that are adapted to survive in harsh conditions colonize the site (Dobson et al. 1997). Increasingly, competitive interactions will structure the community, whereby pioneer species are replaced by species that are superior competitors (Dobson 1997). This increased competition should eventually lead to community stability (Anderson 2007).

The definition of stability is ambiguous in the context of succession (Drury \& Nisbet 1973); however, many authors have equated stability with compositional turnover (e.g. Anderson 
2007). The rate of species turnover is predicted to be greatest at the earliest stages of succession (Drury \& Nisbet 1973). This pattern occurs as the regional species pool becomes exhausted and the rate of competition increases as a community assembles, making it more difficult for new species to colonize (Tilman 1997). There are different responses of turnover expected for different theories of succession; the classical theory of Clements (1916) predicts spikes in turnover rate at each discrete community transition. However, if species are independent units (Gleason 1926) then turnover will be high initially and then decline to a continuous low level (a decelerating decrease). Anderson (2007) showed this response to be common in plant and arthropod successions.

If the reassembly of biotic communities after disturbance is predictable then species diversity may be expected to follow one of three possible trends. If succession leads to increased structural heterogeneity then species richness and diversity should increase (Odum 1969). If all the components of the species assemblage are present at the beginning of succession (Egler 1954) diversity and richness are maximized in the early stages of succession. The mid-stages of succession, however, may be the stages at which the species that are capable of establishing have done so, but competition has not yet filtered the species assemblage, leading to the highest levels of diversity (Howard \& Lee 2003). Therefore, an initial increase in species richness and diversity will be followed in the later stages of succession by a decline, in the absence of further disturbance (Connell 1978).

Here we report on a restoration program that relies on successional processes to restore coastal dune forests destroyed by mining (see van Aarde et al. 1996a). The program began in 1977, and our research initiatives commenced during 1991. Several of our earlier papers (e.g., Ferreira and van Aarde 1996, van Aarde et al.1996a, 1996b, Kritzinger and van Aarde 1998, 
Grainger et al. 2011) implied that the recovery of communities on these sub-tropical dune forests is consistent with models of succession i.e. deterministic. However, none focused on evaluating if successional patterns underlie forest regeneration following rehabilitation, as practiced here. In this paper, we wish to ascertain if the assumption that succession is a valid model for the restoration of coastal dune forest is correct. We assess 4 community level trends expected to result from ecological succession. Several of our previous papers have addressed the convergence of regenerating coastal dune forest with an undisturbed reference forest, so we will not address this aspect of succession herein (e.g., van Aarde et al. 1996b, Davis et al. 2003, Redi et al. 2005, Wassenaar et al. 2005). We used data on trees and herbaceous plants from regenerating coastal dune forests to determine: 1) if the rate of species turnover decreases as coastal dune forest develops; 2) if there is a sequence of changing species "types" from pioneer species adapted to harsh conditions to species adapted to high levels of competition; 3 ) if this sequence of types is directional and consistent across all sites with similar climatic conditions; and 4) if species diversity increases, decreases, or fluctuates. 


\section{Methods}

\section{Study Sites and Restoration Process}

The study area included circa $60 \mathrm{~km}$ of coastline between Richards Bay Town $\left(28^{\circ} 43^{\prime} \mathrm{S}\right.$, $\left.32^{\circ} 12^{\prime} \mathrm{E}\right)$ and the Sokhulu forest $\left(28^{\circ} 27^{\prime} \mathrm{S}, 32^{\circ} 25^{\prime} \mathrm{E}\right)$ in KwaZulu-Natal, South Africa. The climate is humid and subtropical, with mean annual rainfall of $1488 \pm 447.3 \mathrm{~mm}$ [mean $\pm \mathrm{SD}, n$ = $34 \mathrm{yr}$ between 1976 and 2009; data courtesy of Richards Bay Minerals (RBM), $28^{\circ} 41.153 \mathrm{~S}$ $32^{\circ}$ 8. $\left.251 \mathrm{E}\right]$. Rainfall peaks in February, and the mean $( \pm \mathrm{SD})$ temperature is $23.8 \pm 3.50{ }^{\circ} \mathrm{C}$ (monthly temperature between 2006 and 2009 (data courtesy of RBM)). These coastal dunes have been mined for minerals since 1977 (van Aarde et al. 1996a).

RBM aims to return indigenous coastal dune vegetation to one third of its mined area. The mining process (described in full in van Aarde et al. 1996a) destroys all vegetation in front of the mine-pond. Prior to mining, the topsoil is removed and stockpiled. Immediately postmining, sand dunes are mechanically reshaped and topsoil replaced. The topsoil is then stabilized using drift-fencing and seeded with exotic annual plants (sunhemps, Crotolaria sp. and sunflowers, Helianthus sp.). These annuals do not successfully reproduce in regenerating sites and are absent past the third year of regeneration (Conservation Ecology Research Unit, University of Pretoria, unpublished data). We refer to this stabilization of dunes and return of topsoil as the "kick-start" to succession (van Aarde et al. 1996a, van Aarde et al. 1996c), after which there is minimal management intervention (removal of non-native plant species that successfully disperse to the sites and herbivores), and subsequently the restoration relies on natural successional processes (van Aarde et al. 1996a, van Aarde et al. 1996b).

\section{Data Collection}


We conducted trees surveys in 1999, 2001 and 2005 in 7 (6 in 1999) restored sites, following the methods described by Wassenaar and others (2005). We identified self-supporting woody plants greater than $1.7 \mathrm{~m}$ in height in $716 \times 16-\mathrm{m}$ quadrats per site. In 2009 , we used the Point-Centre Quarter method (PCQ) along randomly located transects that ran perpendicular to the sea (Cottam and Curtis 1956).

To survey the herbaceous plant community, we identified and counted all plant species below $1 \mathrm{~m}$ in height in 10 randomly located (5 in 2003) plots in each rehabilitating site and in the undisturbed reference forest (Wassenaar et al. 2005). A plot consisted of 10, 1- $\mathrm{m}^{2}$ quadrats placed in a 2 x 5-m pattern with 5 m separating each quadrat. Data were collected in 1995, 1999, 2003, and 2005 (Table 1). Tree seedlings $(<1.7 \mathrm{~m}$ in height) were not included in the analyses.

\section{Analysis}

Previous work in the study region has relied on the chronosequence approach (e.g., Ferreira and van Aarde 1997, Davis et al. 2003, Wassenaar et al. 2005), which has been criticised because it ignores site-specific effects (Chazdon et al. 2007, Johnson and Miyanishi 2008). To determine if trends in successional patterns were not just artefacts of the chronosequence, we identified trends (where data allowed) within individual sites across several survey events and compared them to trends across a chronosequence (substituting space for time). We used data from all of our 16 (at most) survey years to produce each chronosequence. We could not use data from the same site at different ages because this would have violated the assumptions of a chronosequence. Instead, we constructed simulated chronosequences by a stratified random sampling procedure, where a site was only included once within each chronosequence. The data could come from any one of the survey years. This procedure was repeated 1000 times, and the mean values were used in the chronosequence. 
To test the assumption that sites of a similar age would have similar composition we used non-metric multidimensional scaling (NMDS) using the function 'metaMDS' of the package VEGAN (v.1.15-3; Oksanen et al. 2008) in the R statistical software (v. 2.8.1; R Core Team Development 2008). We used the Bray-Curtis dissimilarity index and set the 'zerodist' argument to add a small positive value to zero dissimilarities. We confirmed patterns of community composition shown in the NMDS using analysis of similarity (using the function 'anosim' in R's VEGAN package). Further, to test if changes in species composition were related to the age of sites we used a Mantel test using the function 'mantel' once again in the VEGAN package. This test measures concordance between two distance matrices - community similarity versus time in this instance. We determined species habitat associations from published sources for herbaceous plants (Pooley 1998), trees (Coates-Palgrave 2003), and birds (Gibbon 2006). No independent sources of information exist for millipede habitat associations.

To test the assumption that pioneers do not replace themselves, we used diameter at breast height $(\mathrm{DBH})$ measurements from the 2009 tree survey to create size class distribution plots for all sites combined. We only assessed the most abundant tree species, including Sweet thorn (Acacia karroo; the most abundant tree in the rehabilitating sites), White stinkwood (Celtis africana), Turkey berry (Canthium inerme), Coast silver oak (Brachlaena discolour), Dune false currant (Allophylus natalensis), Pigeon wood (Trema orientalis), Coastal golden leaf (Bridelia micrantha), Tassel berry (Antidesma venosum) and Black monkey-orange (Strychnous gerrardii). We combined data for Coastal red milkwood (Mimusops caffra) and Bush red milkwood (M. obovata) as well as data for Natal mahogany (Trichilia emetica) and Forest mahogany (T. dregeana) as distinction between these related species is difficult. 
We calculated species turnover as the average of species gains and losses between survey events, expressed as a proportion of the mean species richness during the survey period (Anderson 2007). Gains were defined as the number of new species added to the community, and losses were defined as the number of species lost from the community. We did not consider the reappearance of a previously present species in the community as ecologically significant; rather, we assumed that this was an artefact of sampling or a stochastic event. Therefore, these data were not counted in the calculation of turnover. We used regression analysis to assess how much variation in turnover could be attributed to regeneration age.

We calculated species richness as the number of species per plot. We calculated species diversity using the Shannon index of diversity and evenness using the Smith and Wilson evenness index ( $\mathrm{E}_{\mathrm{var}}$; Smith and Wilson 1996). We compared the regression slopes of individual sites to those predicted by randomized chronosequences using the method described by Zar (1984) and calculated in the program GraphPad Prism 3.0. Data were tested for departure from linearity using a runs test in GraphPad Prism 3.0.

\section{Results}

\section{Species turnover}

Species turnover for both taxa followed the expected pattern of a decelerating decline in turnover rate with increased regeneration age (Figure 1). Regeneration age explained at least $30 \%$ of the variation in turnover rate (non-linear regression, trees: $\mathrm{R}^{2}=0.31$, herbaceous plants: $\left.\mathrm{R}^{2}=0.50\right)$

\section{Change in life-history traits}


The stress of the NMDS ordinations was relatively high (>20\%) with a two-dimensional ordination (i.e., $k=2$ ); however, the results of the ANOSIM confirmed that community composition for both taxa differed between site ages (trees: $\mathrm{R}=0.47, p<0.001$; herbaceous plants: $\mathrm{R}=0.31, p<0.001$, Figure 2 ). The tree community ordination showed clearer convergence between the plots in sites of a similar age (Figure 2a; NMDS, stress $=19.00, \mathrm{k}=3$, non-metric fit $r^{2}=0.98$, linear fit $\left.r^{2}=0.93\right)$. For the herbaceous plants, plots in sites aged between 1 and $5 \mathrm{yr}$ old, and those between 6 and $10 \mathrm{yr}$ old were separated from the plots $>11 \mathrm{yr}$ old, which overlapped considerably (Figure 2b; NMDS, stress $=17.25, \mathrm{k}=3$, non-metric fit $\mathrm{r}^{2}=0.95$, linear fit $\left.\mathrm{r}^{2}=0.83\right)$. The Mantel test results confirm these changes in species composition with regeneration age (Mantel test; trees: $\mathrm{r}=0.48, p<0.001$; herbaceous plants: $\mathrm{r}=0.38, p<0.001$ ). For both trees and herbaceous plants species identity appears to broadly shift from species adapted to harsh environments to those more typical of forests (Figure 2). Of the 11 tree species for which we assessed size class distributions only Acacia karroo and Antidesma venosum did not show the reverse-J pattern indicative of active recruitment (we only show results for four species in Figure 3).

Trends in species richness, diversity and evenness

Site and taxon specific chronosequential trajectories for richness, diversity, and evenness were idiosyncratic (Table 2). Herbaceous plant richness and diversity decreased in the youngest site with increased age and increased in older sites. This pattern was also evident in the youngest site for tree evenness (Table 2).

\section{Discussion}


Our findings suggest that succession is a valid model of coastal dune forest restoration. The rate of succession (species turnover) exhibited by all the taxa showed a decelerating decrease; sites that have recently undergone disturbance had a greater compositional turnover. As communities aged, the number of available microsites apparently declined, and interspecific competition may have increased (Gross 1980, Tilman 1997). Compositional stability is a key concept in the theory of succession (McCook 1994, Anderson 2007), and the declining decrease in the rate of turnover fits with Egler's (1954) theory of initial floristics, Gleason's (1926) individualistic theory of succession, and Connell's (1978) intermediate disturbance hypothesis. This pattern does not support Clements's (1916) classical theory of succession.

The shift in species composition from species adapted to harsh environments to those species that are superior competitors appears to be ubiquitous in forest succession (example.g., Kardol et al. 2005, Cutler et al. 2008, Lebrija-Trejos et al. 2008). However, Chazdon and colleagues (2007) and Johnson and Miyanishi (2008) suggest that this trend in species compositional changes is an artefact of the chronosequence approach. Our results dispute this, as we have demonstrated that sites of a similar age share a similar species composition of coastal dune forest trees and herbaceous plants. This change in species composition may be driven by differences in species longevity, tolerance to shade, eventual size (a competitive advantage for forest trees), timing of colonization, and patterns of recruitment (Fajardo and González 2009). It is evident from the tree community in particular, that recruitment of A. karroo, the first tree to colonize regenerating sites, is limited under a canopy consisting of adults of the same species; whereas, other longer-lived pioneer and forest species were actively recruiting. This pattern fits the predictions of Connell and Slayter's (1977) facilitation mechanism of succession. Without empirical knowledge of species tolerance to shade, it is difficult to conclude that light intensity is 
driving the replacement of plant species in coastal dune forest. However, this is a plausible driver of plant species replacement (Woods 2000, Fajardo and González 2009, but see Dietze and Clarke 2008 for counter arguments to this paradigm), and changes in the tree community may influence changes in the other taxa (Kritzinger and van Aarde 1998).

Trends in species richness and diversity for both trees and herbaceous plants appeared to match expectations overall. As sites aged, they increased in the number and diversity of species. For the herbaceous plants, the youngest site included in our survey (established in 2000, 3 to $5 \mathrm{yr}$ old) decreased in species richness as it aged, which could be consistent with Egler's (1954) initial floristics model. However, this is unlikely, as older sites still gained species with time. The loss of species was more possibly the result of a change in habitat type from grassland to scrub and woodland.

The differences in chronosequence predictions and observed dynamics, although small, highlight an important proviso when using the chronosequence approach. Both regional scale climatic perturbations, such as drought, and site specific differences in the response to disturbance may obscure trends in diversity and richness (Foster and Tilman 2000, Svensson et al. 2009).

\section{Succession Drives Coastal Dune Forest Restoration}

The patterns of age-related species turnover, trends in species type, richness, diversity, and evenness within regenerating coastal dune forest followed the trends expected from Gleason's (1926) individualistic model of successional theory. Gleason's model follows many of the same predictions of trends in communities over time as Clements's (1916) classical model. The difference is that in Gleason's (1926) model community properties are the sum of individual 
species and these species will appear and disappear in a successional sere as independent units. Our observational study can only hint at the mechanisms of change in species composition over the course of succession. To identify the mechanism that is driving these changes, we may have to change the focus of our research from the observational to the experimental. Successional theory does provide hypotheses that can be tested experimentally; for example, Connell and Slayter's (1977) 3 pathways of community succession: facilitation, inhibition, or tolerance (although see McCook 1994, for a critique of these models) must be an avenue of future research at the study site. In addition, we must gather more information on the natural history of species in the regenerating coastal dune forest to fully understand the processes of forest regeneration.

Based on our assessment, succession (Gleason's 1926 individualistic model) is a valid model for the restoration of sub-tropical coastal dune forests. However, departures from the expected patterns do occur, which are likely the result of global, regional, or local scale disruptions and disturbance (Trimble and van Aarde 2011) and landscape composition ( Grainger et al. 2011). It is imperative that any restoration project that relies on successional-based management allows for and expects external disruptions to the pattern of succession (Walker and del Moral 2003). In fact, continued disruption and disturbance should be embraced as a natural part of ecosystem dynamics. 


\section{Acknowledgements}

We thank the University of Pretoria, Richards Bay Minerals, and the South African Department of Trade and Industry for logistical and financial support. We acknowledge the help of Michelle Boshoff of Richards Bay Minerals for facilitating fieldwork. We are indebted to many research assistants, graduate students, and post-graduate students who have participated in fieldwork over the last $18 \mathrm{yr}$.

\section{References}

Anderson, K.J. 2007. Temporal patterns in rates of community change during succession. The American Naturalist 169:780-793.

Baniya, C.B., T. Solhøy and O.R. Vetaas. 2009. Temporal changes in species diversity and composition in abandoned fields in a trans-Himalayan landscape, Nepal. Plant Ecology 201:383-399.

Chazdon, R.L., S.G. Letcher, M. van Breugal, M. Martínez-Ramos, F. Bongers and B. Finegan. 2007. Rates of change in tree communities of secondary Neotropical forests following major disturbances. Philosophical Transactions of the Royal Society B 362:273-289.

Clements, F.E. 1916. Plant succession: An analysis of the development of vegetation. Washington, D.C.: Carnegie Institution of Washington, Washington D.C. United States of America.

Coates-Palgrave, K. 2003. Trees of southern Africa. Struik Publishers, Cape Town, South Africa.

Connell, J.H. 1978. Diversity in tropical rainforests and coral reefs. Science 199:1302-1310. 
Connell, J.H., and R.O. Slatyer. 1977. Mechanisms of succession in natural communities and their role in community stability and organisation. The American Naturalist 111:11191144.

Cottam, G., and J.T. Curtis. 1956. The use of distance measures in Phytosociological sampling. Ecology 37:451-460.

Cowles, H.C. 1901. The physiographic ecology of Chicago and vicinity: A study of the origin, development, and classification of plant societies. Botanical Gazette 31:73-108, 145-182.

Cutler, N. 2009. Long-term primary succession: a comparison of non-spatial and spatially explicit inferential techniques. Plant Ecology DOI 10.1007/s11258-009-9692-2

Cutler, N.A., L.R. Belya, and A.J. Dugmore. 2008. The spatiotemporal dynamics of a primary succession. Journal of Ecology 96:231-246.

Davis, A.L., R.J. van Aarde, C.H. Scholtz, and J.H. Delport2003. Convergence between dung beetle assemblages of a post-mining vegetation chronosequence and unmined dune forest. Restoration Ecology 11:29 - 42.

Dietze, M.C., and J.S. Clarke. 2008. Changing the gap dynamics paradigm: Vegetative regeneration control on forest response to disturbance. Ecological Monographs 79:331347.

Dobson, A.P., A.D. Bradshaw, and A.J.M. Baker. 1997. Hopes for the future: Restoration Ecology and Conservation Biology. Science 277:515-522.

Egler, F.E. 1954. Vegetation science concepts I. Initial floristic composition a factor in old-field vegetation development. Vegetatio 4:412-417. 
Fajardo, A., and M.E. González. 2009. Replacement patterns and species coexistence in an Andean Araucaria-Nothofagus forest. Journal of Vegetation Science 20:1176-1190.

Ferreira, S.M. and R.J. van Aarde. 1996. Changes in community characteristics of small mammals in rehabilitating coastal dune forests in northern KwaZulu/Natal. African Journal of Ecology 34: 113 - 130.

Ferreira, S.M. and R.J. van Aarde. 1997. The chronosequence of rehabilitating coastal dune forests: do small mammals confirm it? South African Journal of Science 93: 211 - 214.

Foster, B.L., and D. Tilman. 2000. Dynamic and static views of succession: Testing the chronosequence approach. Plant Ecology 146:1-10.

Gibbon, G. 2006. Roberts' multimedia birds of southern Africa version 3.3. South African Birding, Westville, South Africa.

Gleason, H.A. 1926. The individualistic concept of the plant association. Bulletin of the Torrey Botanical Club 53:7-26.

Grainger, M.J., R.J., van Aarde, and T.D. Wassenaar. 20112011. Landscape composition influences the restoration of subtropical coastal dune forest. Restoration Ecology 19: 111120.

Gross, K.L. 1980. Colonization by Verbascum thapsus (Mullein) of an old-field in Michigan: Experiments on the effects of vegetation. Journal of Ecology 68:919-927.

Hobbs, R.J., L.R. Walker, and J. Walker. 2007. Integrating restoration and succession. Pages 168 -179. in L.R. Walker, J. Walker and R.J. Hobbs (eds), Linking restoration and ecological succession. Springer, New York, United States of America. 
Hodačová, D., and K. Prach. 2003. Spoil heaps from brown coal mining: Technical reclamation versus spontaneous revegetation. Restoration Ecology 11:385-391.

Johnson, E.A., and K. Miyanishi. 2008. Testing the assumptions of chronosequences in succession. Ecology Letters 11:1-13.

Kardol, P., T.M. Bezemer, A. van der Wal, and W.H. van der Putten. 2005. Successional trajectories of soil nematode and plant communities in a chronosequence of ex-arable lands. Biological Conservation 126:317-327.

Kritzinger, J.J. and R.J. van Aarde. 1998. The bird communities of rehabilitating coastal dunes at Richards Bay, KwaZulu-Natal. South African Journal of Science 94: 71 - 78.

Lanta, V., and J. Lepš. 2009. How does surrounding vegetation affect the course of succession: A five-year container experiment. Journal of Vegetation Science 20:686-694.

Lebrija-Trejos, E., F. Bongers, E.A. Pérez-García, and J.A. Meave. 2008. Successional change and resilience of a very dry forest following shifting agriculture. Biotropica 40:422-431.

McCook, L.J. 1994. Understanding ecological community succession: Causal models and theories, a review. Vegetatio 110:115-147.

Oksanen J, P. Legendre, B. O'Hara and M.H.H. Stevens .2007. VEGAN: Community Ecology Package. $\quad \mathrm{R} \quad$ package $1.8-8 . \quad$ http://cran.r-project.org/; $\quad \underline{\text { http://r-forge.r- }}$ project.org/projects/vegan/.

Pooley, E. 1998. A Field Guide to Wild Flowers KwaZulu-Natal and the Eastern Region. Natal Flora Publications Trust, Durban, South Africa. 
Prach, K., and P. Pysek. 2001. Using spontaneous succession for restoration of human-disturbed habitats: Experience from central Europe. Ecological Engineering 17:55-62.

R Development Core Team 2008. R: A language and environment for statistical computing. $\mathrm{R}$ Foundation for Statistical Computing, Vienna, Austria. ISBN 3-900051-07-0, URL http://www.R-project.org.

Redi, B.H., R.J. van Aarde, and T.D. Wassenaar. 2005. Coastal dune forest development and the regeneration of millipede communities. Restoration Ecology 13:284-291.

Řehounková, K., and K. Prach. 2008. Spontaneous vegetation succession in gravel-sand pits: A potential for restoration. Restoration Ecology 16:305-312.

Smith, B., and J.B. Wilson. 1996. A consumer's guide to evenness indices. Oikos 76:70-82.

Suding, K.N., K.L. Gross, and G.R. Houseman. 2004. Alternative states and positive feedbacks in restoration ecology. Trends in Ecology and Evolution 19:46-53.

Svensson, J.R., Lindegarth, M., and H. Pavia. 2009. Equal rates of disturbance cause different patterns of diversity. Ecology 90:496-505.

Tilman, D. 1997. Community invasibility, recruitment limitation, and grassland biodiversity. Ecology 78:81-92.

Trimble, M.J., and R.J. van Aarde. 2011. Widespread pattern of bird decline extends to Africa: determinants of avian diversity loss in coastal dune forests of South Africa. PloS One 6: e16176. doi:10.1371/journal.pone.0016176 
Tsuyuzaki, S. 2009. Causes of plant community divergence in the early stages of volcanic succession. Journal of Vegetation Science 20:959-969.

van Aarde, R.J., M. Coe, and W.A. Niering. 1996a. On the rehabilitation of coastal dunes of KwaZulu-Natal. South African Journal of Science 92:122-124.

van Aarde, R.J., S.M. Ferreira, and J.J. Kritzinger. 1996b. Successional changes in rehabilitating coastal dune communities in northern KwaZulu-Natal, South Africa. Restoration Ecology 4: 334 - 345 .

van Aarde, R.J., S.M. Ferreira, J.J. Kritzinger, and P.J. van Dyk. 1996c. An evaluation of habitat rehabilitation on coastal dune forests in northern KwaZulu-Natal, South Africa. Restoration Ecology 4: 334 - 345.

van Aarde, R.J., S.M. Ferreira, J.J. Kritzinger. 1996d. Millipede communities in rehabilitating coastal dune forests in northern KwaZulu/Natal, South Africa. Journal of Zoology 238: $703-712$.

van Andel, J. and J. Aronson. 2006. Restoration Ecology. Blackwell, Oxford, United Kingdom.

Walker, L.R., and R. del Moral. 2003. Primary succession and Ecosystem Rehabilitation. Cambridge University Press, Cambridge, United Kingdom.

Walker, L.R., and R. del Moral. 2008. Lessons from primary succession for restoration of severely damaged habitats. Applied Vegetation Science 12:55-67.

Walker, L.R., J. Walker, and R. del Moral. 2007. Forging a new alliance between succession and restoration. Pages 1 - 18. in Walker, L.R., J. Walker, and R.J. Hobbs (eds), Linking restoration and ecological succession. Springer, New York, United States of America. 
Wassenaar, T. D., R. J. van Aarde, S. L. Pimm, and S. M. Ferreira. 2005. Community convergence in disturbed sub-tropical dune forest. Ecology 86: 655-666.

Woods, K. 2000. Dynamics in late successional Hemlock-Hardwood forests over three decades. Ecology 81:110-126.

Young, T.P., D.A. Petersen, and J.J. Clary. 2005. The ecology of restoration: historical links, emerging issues and unexplored realms. Ecology Letters 8:662-673.

Zar, J.H. 1984. Biostatistical Analysis. Prentice-Hall, New Jersey, United States of America.

Zedler, J.B. and J.C. Callaway. 1999. Tracking wetland restoration: do mitigation sites follow desired trajectories? Restoration Ecology 7:69-73.

Affiliation: Conservation Ecology Research Unit, Department of Zoology and Entomology, University of Pretoria, Pretoria, South Africa, 0002

*Author for correspondence: matthewjamesgrainger@gmail.com 
Table 1. Survey years and site ages for each rehabilitating coastal dune forest site in KwaZulu-Natal, South Africa, indicated by the year of establishment 1977 to 2003. Surveys for herbaceous plants, and trees took place in different survey years. Highlighted in grey are the survey years for each.

\begin{tabular}{|c|c|c|c|c|c|c|c|c|c|c|c|c|c|c|c|c|c|}
\hline Survey year & 1993 & 1994 & 1995 & 1996 & 1997 & 1998 & 1999 & 2000 & 2001 & 2002 & 2003 & 2004 & 2005 & 2006 & 2007 & 2008 & 2009 \\
\hline \multicolumn{18}{|l|}{ Herbs } \\
\hline \multicolumn{18}{|l|}{ Trees } \\
\hline 1977 & 16 & 17 & 18 & 19 & 20 & 21 & 22 & 23 & 24 & 25 & 26 & 27 & 28 & 29 & 30 & 31 & 32 \\
\hline 1980 & 13 & 14 & 15 & 16 & 17 & 18 & 19 & 20 & 21 & 22 & 23 & 24 & 25 & 26 & 27 & 28 & 29 \\
\hline 1984 & 9 & 10 & 11 & 12 & 13 & 14 & 15 & 16 & 17 & 18 & 19 & 20 & 21 & 22 & 23 & 24 & 25 \\
\hline 1988 & 5 & 6 & 7 & 8 & 9 & 10 & 11 & 12 & 13 & 14 & 15 & 16 & 17 & 18 & 19 & 20 & 21 \\
\hline 1992 & 1 & 2 & 3 & 4 & 5 & 6 & 7 & 8 & 9 & 10 & 11 & 12 & 13 & 14 & 15 & 16 & 17 \\
\hline 1996 & $\mathrm{X}$ & $X$ & $\mathrm{X}$ & $X$ & 1 & 2 & 3 & 4 & 5 & 6 & 7 & 8 & 9 & 10 & 11 & 12 & 13 \\
\hline 2000 & $\mathrm{X}$ & $X$ & $X$ & $\mathrm{X}$ & $X$ & $\mathrm{X}$ & $X$ & $\mathrm{X}$ & 1 & 2 & 3 & 4 & 5 & 6 & 7 & 8 & 9 \\
\hline 2003 & $\mathrm{X}$ & $\mathrm{X}$ & $\mathrm{X}$ & $\mathrm{X}$ & $\mathrm{X}$ & $\mathrm{X}$ & $\mathrm{X}$ & $\mathrm{X}$ & $\mathrm{X}$ & $\mathrm{X}$ & $\mathrm{X}$ & 1 & 2 & 3 & 4 & 5 & 6 \\
\hline
\end{tabular}


Table 2. The slope of the regression lines for species richness, diversity, and evenness for herbaceous plants, and trees occurring in regenerating sites in KwaZulu-Natal, South Africa. The randomized chronosequence is the expected trend, and the individual sites is the observed trend. Asterisks $\left(^{*}\right)$ indicate a significant $(\alpha=0.05)$ difference between the slope of the expected and observed regression line.

\begin{tabular}{llll}
\hline Expected & Observed & \\
\hline Slope of the & $\begin{array}{l}\text { Significantly } \\
\text { non-zero (alpha } \\
=0.05)\end{array}$ & $\begin{array}{l}\text { Slope of the } \\
\text { regression line }\end{array}$ & $\begin{array}{l}\text { Significantly } \\
\text { non-zero (alpha } \\
=0.05)\end{array}$
\end{tabular}

\section{Herbaceous plants - species}

per transect

Randomised chronosequence

$-0.06 \pm 0.20 \quad$ No

18 to 28 years of regeneration

$0.34 \pm 0.14 \quad$ Yes

15 to 25 years of regeneration

$0.61 \pm 0.16^{*} \quad$ Yes

11 to 21 years of regeneration

$0.50 \pm 0.12^{*} \quad$ Yes

7 to 17 years of regeneration

$0.99 \pm 0.12^{*} \quad$ Yes

3 to 13 years of regeneration

$0.17 \pm 0.17 \quad$ No

3 to 9 years of regeneration

$1.25 \pm 0.34^{*} \quad$ Yes

3 to 5 years of regeneration

$-2.82 \pm 0.94^{*} \quad$ Yes

Trees - species per transect

Randomised chronosequence $\quad 0.42 \pm 0.07 \quad$ Yes

14 to 28 years of regeneration

$0.64 \pm 0.15 \quad$ Yes

11 to 25 years of regeneration

$0.058 \pm 0.15^{\star} \quad$ No

8 to 21 years of regeneration

$0.64 \pm 0.14 \quad$ Yes

4 to 17 years of regeneration

$0.58 \pm 0.12 \quad$ Yes

9 to 13 years of regeneration

$0.81 \pm 0.40 \quad$ Yes

5 to 9 years of regeneration

$1.02 \pm 0.30 \quad$ Yes

1 to 5 years of regeneration

$0.71 \pm 0.19 \quad$ Yes

Herbaceous plants - diversity 
Randomised chronosequence $\quad 0.02 \pm 0.00 \quad$ Yes

18 to 28 years of regeneration

$0.03 \pm 0.01 \quad$ Yes

15 to 25 years of regeneration

$0.04 \pm 0.01 \quad$ Yes

11 to 21 years of regeneration

$0.03 \pm 0.01 \quad$ Yes

7 to 17 years of regeneration

$0.06 \pm 0.01^{*} \quad$ Yes

3 to 13 years of regeneration

$0.02 \pm 0.02^{*} \quad$ No

3 to 9 years of regeneration

$0.13 \pm 0.03 \quad$ Yes

3 to 5 years of regeneration

$-0.13 \pm 0.05 \quad$ Yes

Trees - diversity

Randomised chronosequence

$0.08 \pm 0.02 \quad$ Yes

14 to 28 years of regeneration

$0.03 \pm 0.02^{*} \quad$ No

11 to 25 years of regeneration

$0.04 \pm 0.04^{*} \quad$ No

8 to 21 years of regeneration

$0.21 \pm 0.02 \quad$ Yes

4 to 17 years of regeneration

$0.12 \pm 0.03 \quad$ Yes

9 to 13 years of regeneration

$0.17 \pm 0.05 \quad$ Yes

5 to 9 years of regeneration

$0.05 \pm 0.05^{*} \quad$ No

1 to 5 years of regeneration

$0.06 \pm 0.02 \quad$ Yes

\section{Herbaceous plants -}

evenness

Randomised chronosequence

$0.00 \pm 0.01 \quad$ No

18 to 28 years of regeneration

$-0.00 \pm 0.00 \quad$ No

15 to 25 years of regeneration

$-0.01 \pm 0.00 \quad$ No

11 to 21 years of regeneration

$-0.01 \pm 0.00^{*} \quad$ Yes

7 to 17 years of regeneration

$-0.00 \pm 0.00 \quad$ No

3 to 13 years of regeneration

$0.00 \pm 0.01 \quad$ No

3 to 9 years of regeneration

$-0.00 \pm 0.01 \quad$ No

3 to 5 years of regeneration

$0.03 \pm 0.02 \quad$ No

\section{Trees - evenness}

Randomised chronosequence $\quad 0.03 \pm 0.01 \quad$ Yes

14 to 28 years of regeneration

$0.01 \pm 0.00$

Yes 
11 to 25 years of regeneration

8 to 21 years of regeneration

4 to 17 years of regeneration

9 to 13 years of regeneration

5 to 9 years of regeneration

1 to 5 years of regeneration
$-0.01 \pm 0.01^{*} \quad$ No

$-0.00 \pm 0.01^{*} \quad$ No

$0.00 \pm 0.01^{*} \quad$ No

$0.00 \pm 0.00^{*} \quad$ No

$-0.00 \pm 0.01^{*} \quad$ No

$-0.01 \pm 0.00^{*} \quad$ Yes 


\section{Trees}

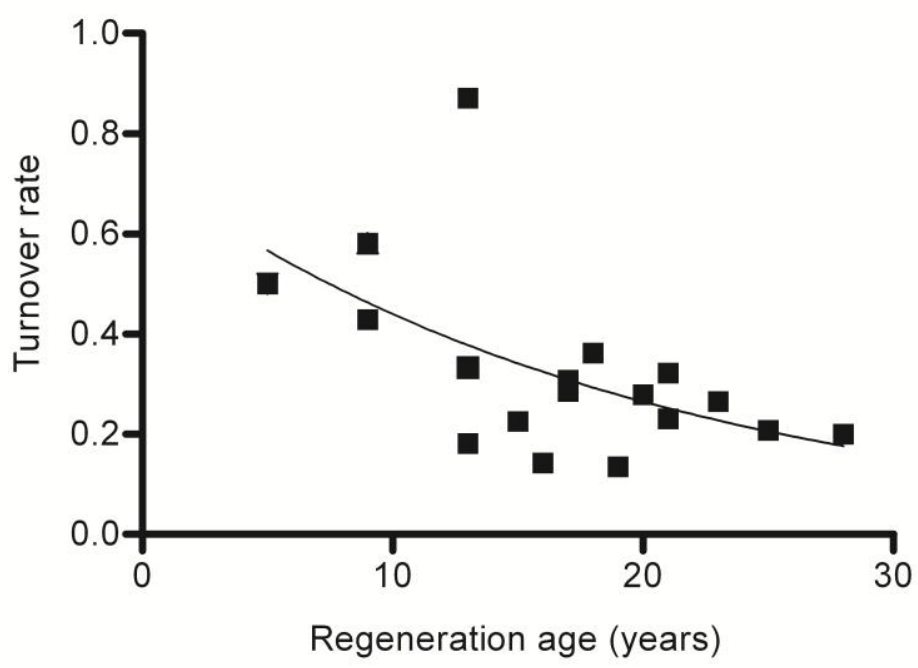

Herbaceous plants

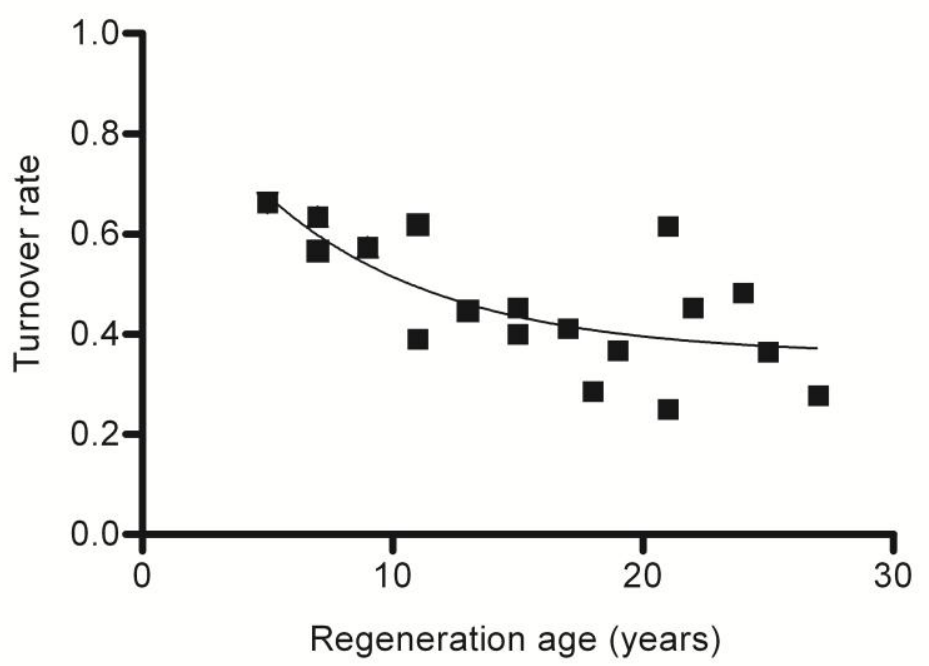

Figure 1. The rate of herbaceuous plant, tree, bird, and millipede species turnover in regenerating coastal dune forests in KwaZulu-Natal, South Africa. . 

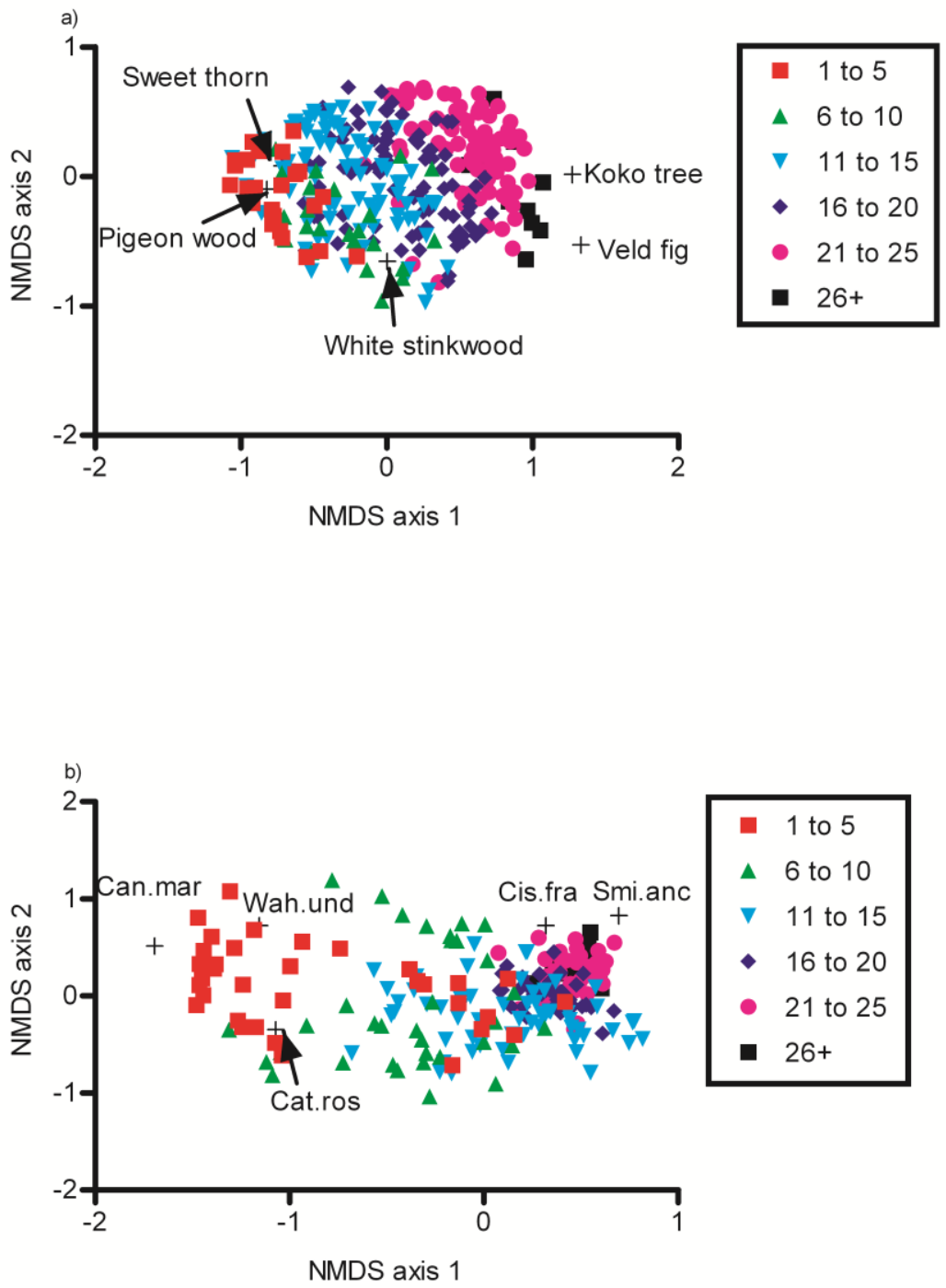
Figure 2. Ordination of regenerating coastal dune forest communities of known age in KwaZuluNatal, South Africa using non-metric multidimensional scaling (NMDS). Sites of similar age (grouped together in 5-yr categories) are indicated by the same symbol. Species are indicated by small black crosses (+) for the: a) trees; b) herbaceous plants. Labels for the herbaceous plants (b) refer to "Can.mar" = Bay bean (Canavalia maritima), "Cat.ros" = Madagascar periwinkle (Catharanthus roseus), "Cis.fra" = Forest grape vine (Cissus fragilis), "Smi.anc" = Wild sarsaparilla (Smilax anceps) and "Wah.und" = Giant bell flower (Wahlenbergia undulata). 
Sweet thorn $(n=1359)$

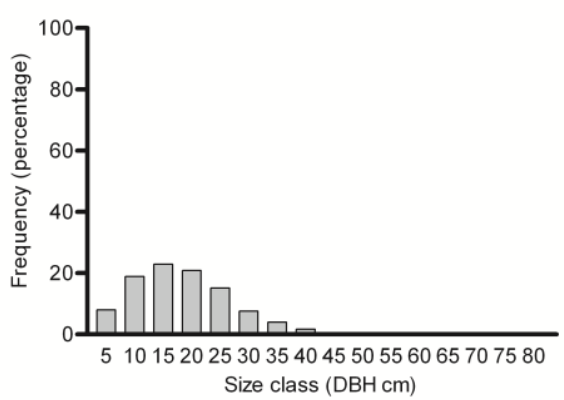

Turkey berry $(n=200)$

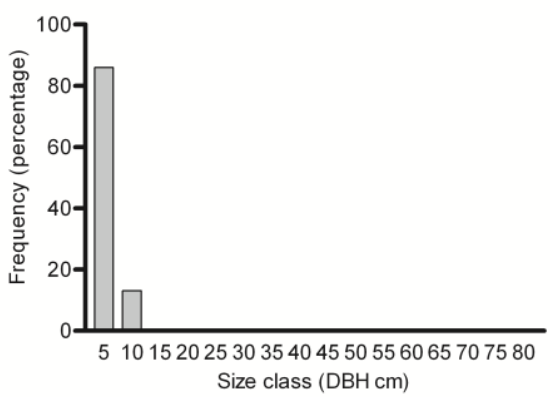

White stinkwood $(n=243)$

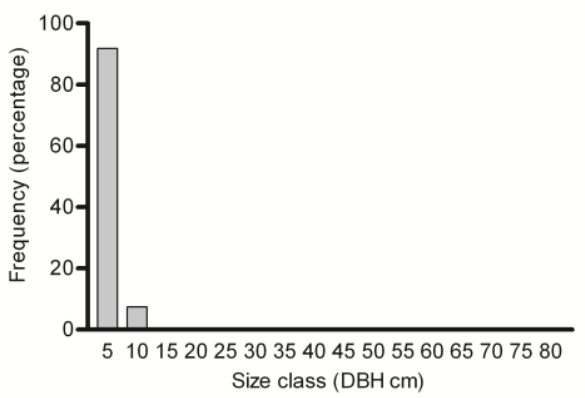

Pigeon wood $(n=158)$

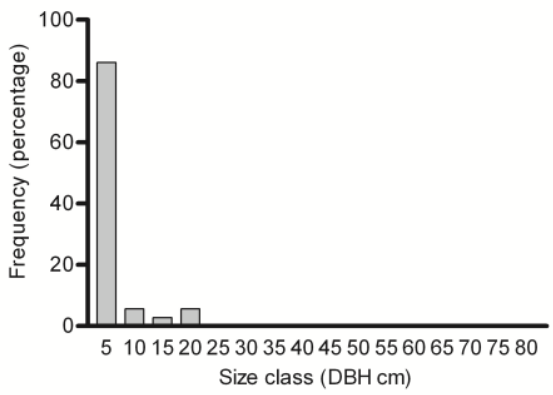

Figure 3. Size class distributions of the dominant pioneer tree Sweet thorn (Acacia karroo), and the most abundant three other tree species (White stinkwood, Celtis africana; Turkey berry, Canthium inerme; Pigeon wood, Trema orientalis) within the regenerating coastal dune forests in KwaZulu-Natal, South Africa. The only tree that did not show a regenerating population is the pioneer Acacia karroo. 